\title{
Application of Fuzzy Control for Iron Ore Sintering Process*
}

\section{Introduction}

Iron- and steelmaking works include complex processes difficult to make precise models and dependent on the skilled operators. The fuzzy set theory makes most use of the operators' heuristic knowledge with the membership function to control the process in place of skilled operators.

An on-line fuzzy control system for feeding return fine has been developed and put into practice in August 1986 for the sintering process of the Fukuyama Works, NKK Corp. (Nippon Kokan K.K).

\section{An On-line Fuzzy Control Model for Feeding Return Fine}

In general the rate of return fine ore largely depends on the sinter quality and changes with the fluctuations in raw materials adherence, sintering operation condition, and sinter ore quality. Therefore uniform supply of return fine ore is important. However, since the whole iron ore sintering process has a dead time of 4 to $5 \mathrm{~h}$, it is difficult to make the precise model by the conventional method.

The essence of fuzzy control is a
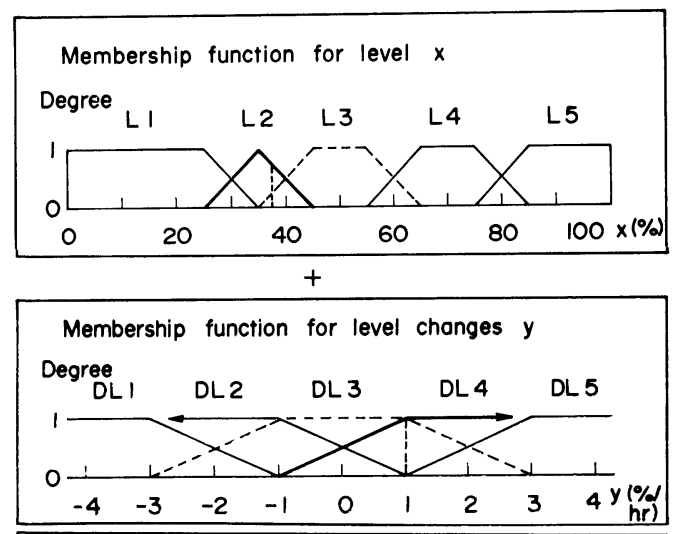

IF $L i$ is $\cdots$ and $D L j$ is $\cdots$, then $Z=A i$ using following table

\begin{tabular}{|c|c|c|c|c|c|c|c|c|c|}
\hline Li & LI & L & 2 & & L3 & & & 4 & L5 \\
\hline$D L J$ & DL2 & OL 2 & $\mathrm{DL} 4$ & $D^{\prime} 1$ & $D L 3$ & DL 5 & $\mathrm{DL} 2$ & DL 4 & DL 4 \\
\hline $\mathrm{Ai}$ & $A I$ & $\Delta 1$ & $\Delta 2$ & $A 2$ & A 3 & A4 & A 4 & A 5 & A5 \\
\hline
\end{tabular}

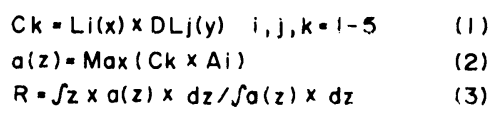

$R=\int z \times a(z) \times d z / \int a(z) \times d z$

Membership function for action z

Degree

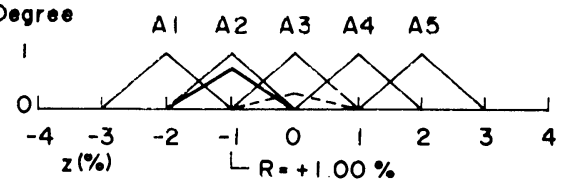

Fig. 1. Membership function.

membership function, representing the experienced operators' heuristic knowledge. Figure 1 shows the membership functions of return fine feeding and procedure for the determination of action value.

In the fuzzy set theory, if $\mathrm{L} i$ represents the $i$-th membership function for level $(x), \mathrm{DL} j$ the $j$-th function for level change $(y)$, and A $i$ the $i$-th function for action $(z)$, the degree of L2 is 0.75 and the degree of L3 is 0.25 , when the hopper level $x$ is $37.5 \%$. The degree of DL4 is 1.0 and the degree of DL3 is 1.0, when the level changes $y$ is $+1 \% / h$. The action function is shown by the solid line for L2, DL4 and A2 and by the broken line for L3, DL3 and A3. The action value calculated as the center of gravity is $1.00 \%$.

\section{Results of On-line Control}

The fuzzy model controls the process more smoothly and continuously than the most skillful operators, as shown in Fig. 2. The fluctuation of return fine hopper level decreased from 12 to $4 \%$ and the amount of return fine ore decreased about $2 \mathrm{~kg} / \mathrm{t}-\mathrm{SR}$.

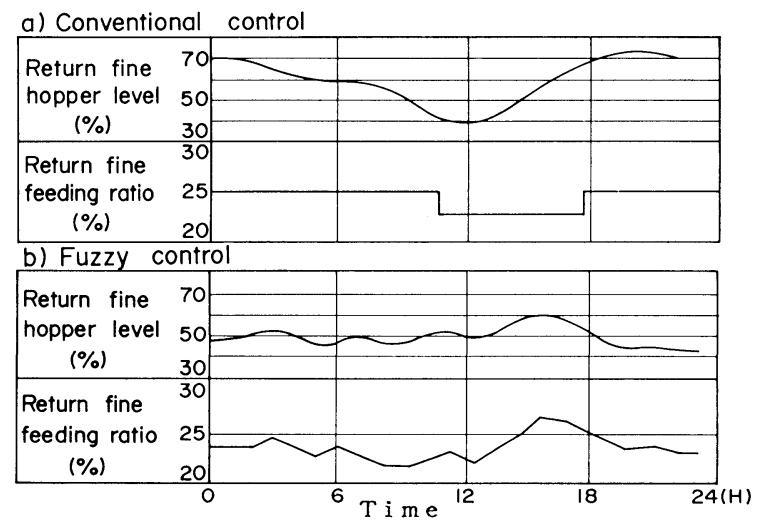

Fig. 2. Result of fuzzy control.

* For further information, write to Iron and Steel Technology Department, NKK Corporation, 1-1, Minamiwatarida-cho, Kawasaki-ku, Kawasaki 210. (C) 1988 ISIJ 